\title{
Design, Synthesis and Photophysical Studies of Improved Xanthene Dye to Detect
} Acetate

J.M. Paredes, ${ }^{a *}$ D. Miguel, ${ }^{a}$ Sandra Resa ${ }^{b}$ M.C. Gonzalez-Garcia ${ }^{a}$, Y. Diaz-Torres ${ }^{a}$, J.M.

Cuerva, ${ }^{b}$ L. Crovetto ${ }^{a *}$

${ }^{a}$ Department of Physical Chemistry, Faculty of Pharmacy, University of Granada, Cartuja Campus, 18071 Granada, Spain.

${ }^{b}$ Department of Organic Chemistry, Faculty of Sciences, University of Granada, C. U. Fuentenueva s/n, 18071 Granada, Spain.

Keywords: Biomarkers, Dye , Fluorescence, acetate detection, FLIM

\begin{abstract}
Development of biomarkers of analytes with interest in clinic is an important field of study. In this work, we synthesized and analyzed the new fluorescent acetate-biomarker, Iso-PG. The mechanism of detection is the acetate buffer mediated proton transfer reaction. The rate constants involved were obtained, and we measured the change in the fluorescence lifetime produced as a consequence of the presence of acetate in the medium. Finally, we checked its potential use as acetate biomarker in synthetic serum.
\end{abstract}

\section{Introduction}

The development of new tools to diagnose and treat current illnesses is nowadays based on the knowledge of how processes occur at celular level. In this context, the use of fluorescent molecules to detect and quantify key analytes inside cells is one of the more dominant approaches. These compounds are then useful tools in sensing a wide variety of analytes ${ }^{[1]}$, as enzimatic activity markers ${ }^{[2]}$ and have also been used in superresolution techniques. ${ }^{[3]}$ Among the huge amount of fluorescent compounds employed in fluorescence microscopy techniques, xantene derivatives have been extensively used due to their high absorption and excellent fluorescent properties ${ }^{[4]}$. 
In a recent paper we investigated the photophysics of new fluorinated fluorescein derivatives, ${ }^{[5]}$ based on an structural combination of the so-called Tokyo ${ }^{[6]}$ and Pennsylvania Green family. ${ }^{[7]}$ Remarkably, these xanthenes showed both the characteristic ESPT reaction promoted by the presence of apropiate buffer and the "on/off" fluorescent character.

On the other hand, alcoholism is one of the most important economical, social and medical problems in the world. One of the biomarkers commonly used for the detection of excessive alcohol consumption and alcoholism is the concentration of acetate anion.. Acetate is formed due a second oxidative step from acetaldehyde. When ethanol is oxidized, the levels of acetate are fastly increased so the presence of this alcohol in the blood can be detected by the maintenance of this high level constant..[8-9]

The fluorescence kinetics and the deterministic and the numerical identifiability of the model of the intermolecular ESPT reaction in presence of adequate proton donor/acceptor have been previously studied [10-11]. This model stablishes the need of using dyes with $\mathrm{p} K_{\mathrm{a}}$ values comparable to $\mathrm{p} K_{\mathrm{a}}$ of the proton donor/acceptor of interest to have a maximal effect on the lifetime and obviously on the rate constant. That is, the effect is magnified when there is an exact concordance between both $\mathrm{p} K \mathrm{as}$.Therefore, fine tuning of the fluorophore is required to obtain the best response and selectivity. Based on it, we have synthesized a new Pennsylvania-based dye presenting an isopropyl group as substituent (Iso-PG) in order to obtain a $\mathrm{p} K_{\mathrm{a}}$ closer to acetate buffer and thus improve ESPT reaction, with the aim to be useful not only in the determination of acetate in human pathologies where its metabolism is involved, as tumors or alcoholism[12-14] but also in microbiology where is important in prokaryotic metabolism depending on the bacteria density[15] or in fast growing microbial culture.[16] The effect of substituent in the $\mathrm{p} K_{\mathrm{a}}$ values of xanthenes has been previously shown[17] .

In this paper, the ground-state equilibrium between the neutral and anionic forms of the dye were explored first. Next, the acetate buffer-mediated ESPT reactions and the relevant kinetic model and dynamics were studied in detail by means of steady-state and time-resolved fluorescence measurements and compared with the previously dyes. Finally, the applicability of the dye for quantification acetate concentration in artificial blood plasma solution by FLIM was also analyzed. 


\section{Synthesis}

Iso-PG was prepared based on a synthetic strategy previously described by our group [5, 18]. Thus, organilithium derivative of 1-bromo-4-isopropyl-2-methoxybenzene[19] was added to previously described MOM-protected ketone, ${ }^{[5]}$ affording after acidic hydrolysis iso-PG in good yield (See Scheme 1 and SI for more details).<smiles>COc1cc2oc3cc(OC)c(F)cc3c(=O)c2cc1F</smiles>

II

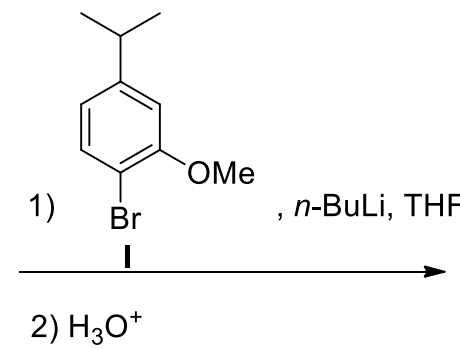

2) $\mathrm{H}_{3} \mathrm{O}^{+}$<smiles>COc1cc(C(C)C)ccc1-c1c2cc(F)c(=O)cc-2oc2cc(O)c(F)cc12</smiles>

Iso-PG

Scheme 1. Synthesis of Iso-PG.

\section{Photophysics Studies}

\section{$\underline{\text { Absorption measurements and ground-state equilibria }}$}

The visible absorption spectra of aqueous solutions of Iso-PG as a function of $\mathrm{pH}$ in the range between 3.48 and 9.73 were recorded. $\mathrm{pH}$ variation changes in absorbance were clearly observed. Figure 1 shows a change in absorption spectra of solutions at different $\mathrm{pH}$ values due to ground-state proton reactions, that it is known that occurs in regions of $\mathrm{pH}$ dictated by the ground-state $p K_{a}$ values. An isosbestic point can be distinguished around $446 \mathrm{~nm}$ suggesting the presence of two species in chemical equilibrium at the experimental conditions used. At high $\mathrm{pH}$ values absorption spectra showed a maximum at $491 \mathrm{~nm}$ that decreased when $\mathrm{pH}$ diminished. At acid $\mathrm{pH}$ values, absorption spectrum presents two maxima at 477 and $452 \mathrm{~nm}$, both less intense than the one observed at basic $\mathrm{pH}$. 


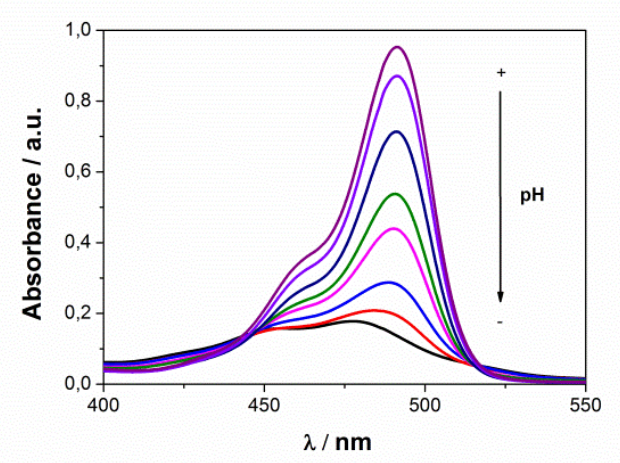

Figure 1. Absorption spectra of Iso-PG $\left(4 \times 10^{-5} \mathrm{M}\right)$ at different $\mathrm{pH}$ values $(3.48,4.04,4.35$, $4.66,4.92,5.37,6.28$ and 9.73)

Chemical structure of the dye, absorption spectra and previous studies of analogous structures[5, 20] suggest that in this $\mathrm{pH}$ range Iso-PG presents two absorbing prototropic forms corresponding to neutral $(\mathrm{N})$ and anionic (A) structures.

If a neutral/anion system follows Beer's law, at any wavelength $\left(\lambda_{\mathrm{abs}}\right)$ and $\mathrm{pH}$, the absorbance $(A)$ is given by the expression

$$
A\left(\mathrm{p} H, \lambda_{a b s}\right)=C\left(\sum_{i} \alpha_{i}\left(\mathrm{p} H, \mathrm{p} K_{N-A}\right) \varepsilon_{i}\left(\lambda_{a b s}\right)\right) d
$$

where $C$ is the total concentration of the dye, $d$ is the optical path length, $\varepsilon_{i}\left(\lambda_{a b s}\right)$ is the wavelength-dependent molar absorption coefficient of the $i$ th prototropic form of the dye, and $\alpha_{i}\left(\mathrm{pH}, \mathrm{p} K_{\mathrm{N}-\mathrm{A}}\right)$ is the fraction of the dye in the $i$ th prototropic form, which depends on both $\mathrm{p} H$ and $\mathrm{p} K_{\mathrm{N}-\mathrm{A}}$.

$\alpha_{N}=\frac{\left[H^{+}\right]}{\left[H^{+}\right]+K_{N-A}}$

$\alpha_{A}=\frac{K_{N-A}}{\left[H^{+}\right]+K_{N-A}}$

The global fit of the entire absorbance, A, vs. $\mathrm{pH}$ vs. $\lambda_{\text {abs }}$ surface to the corresponding acid-base equilibrium equations allows the determination of the molar absorption coefficients $\varepsilon_{\mathrm{i}}(\lambda \mathrm{abs})$ of the two acid-base species and the $\mathrm{pK}_{\mathrm{a}}$. In this global fitting, the apparent $\mathrm{p} K_{\mathrm{a}}^{\mathrm{app}}$ was a linked parameter over the whole surface, while $\varepsilon_{i}\left(\lambda_{\mathrm{abs}}\right)$ were locally 
adjustable parameters at each wavelength for each species. Plots of the individual $A / C$ vs $\mathrm{pH}$ curves at different wavelengths and the generated curves from the fitting are shown in Figure 2. Fitted curves allow recover a $\mathrm{p} K_{\mathrm{a}}^{\text {app }}$ value of $4.91 \pm 0.04$, very similar to the acetic acid/acetate buffer $\mathrm{pK}_{\mathrm{a}}$ value (4.76).

The global fit also allows the calculation of the molar absorption coefficients for both neutral and anion species. These values are represented in figure $2 \mathrm{~B}$, which shows a consistent isosbestic point at $446 \mathrm{~nm}$.

A

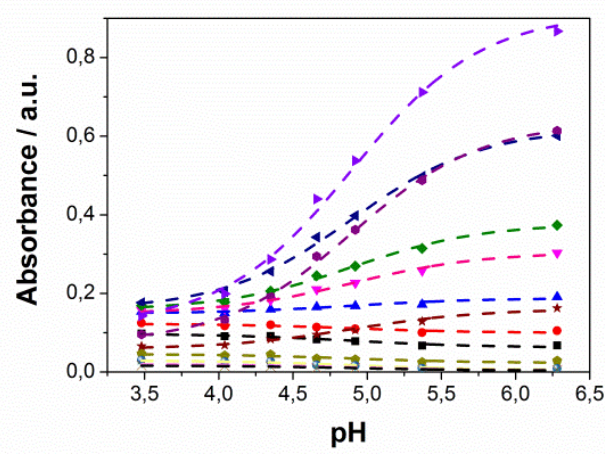

B

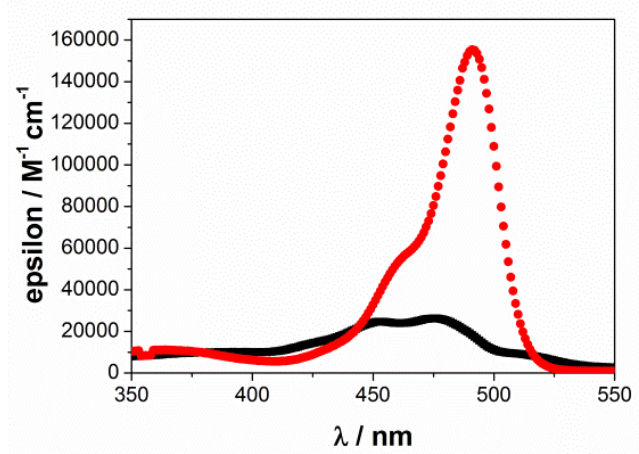

Figure 2. A) Fitted curves of equation 1 to experimental data from Figure 1. B) Calculated molar absorption coefficient at different wavelength for the neutral (black squares) and anion (red circles) forms of Iso-PG

\section{Steady-State studies}

The total fluorescence signal $F\left(\lambda_{\mathrm{ex}}, \lambda_{\mathrm{em}},\left[\mathrm{H}^{+}\right]\right)$at a defined proton concentration $\left[\mathrm{H}^{+}\right]$due to excitation at $\lambda_{\text {ex }}$ and observed at emission wavelength $\lambda_{\text {em }}$ can be expressed as

$$
F\left(\lambda_{\text {ex }}, \lambda_{\text {em }},\left[\mathrm{H}^{+}\right]\right)=\frac{F_{\min }\left[\mathrm{H}^{+}\right]+F_{\max } K_{\mathrm{a}}}{K_{\mathrm{a}}+\left[\mathrm{H}^{+}\right]}
$$

where $F_{\min }$ indicates the fluorescence signal of the neutral form of the dye and $F_{\max }$ denotes the fluorescence signal of the anion form of Iso-PG. To obtain these parameters, samples at different $\mathrm{pH}$ values were measured (see Figure 3A). As can be appreciated, the signal is enormously reduced with the decrease of the $\mathrm{pH}$ value. This interesting 
"on/off" characteristics could allow the use of this dye as $\mathrm{pH}$ probe around the $\mathrm{pK}$ a of the chemical equilibrium between the neutral and anionic species. Fitting equation 4 to the fluorescence data $F\left(\lambda_{\mathrm{ex}}, \lambda_{\mathrm{em}},\left[\mathrm{H}^{+}\right]\right)$as a function of $\left[\mathrm{H}^{+}\right]$is shown in Figure $3 \mathrm{~B}$, yielding values for $K_{\mathrm{a}}, F_{\min }$, and $F_{\max }$. Data recover shown values of $\mathrm{p} K_{\mathrm{a}}=5.038$

A

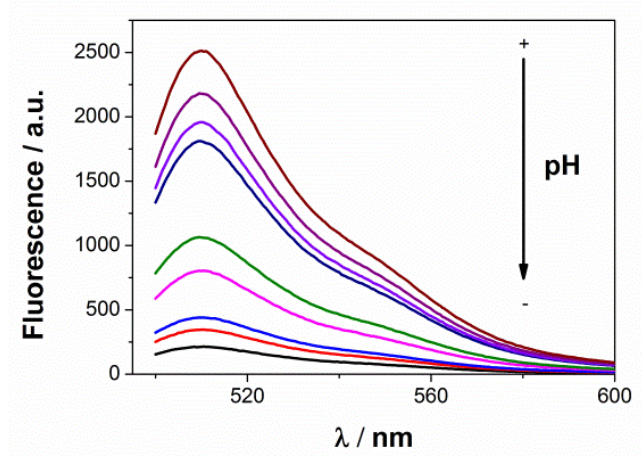

B

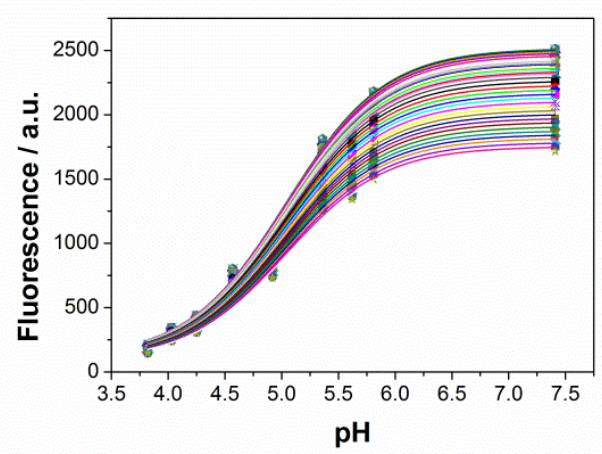

Figure 3. A) Steady-state emission spectra $\left(\lambda_{\mathrm{ex}}=485 \mathrm{~nm}\right)$ of $1 \times 10^{-6} \mathrm{M}$ Iso-PG aqueous solutions at different $\mathrm{pH}$ from 3.40 to $7.45 \mathrm{~B}$ ) Plot of the experimental steady-state fluorescence intensity versus $\mathrm{pH}$, from solutions of $1 \times 10^{-6} \mathrm{M}$ Iso-PG without acetate buffer. and fitted plot from equation 4 to experimental data (Lines)

Quantum yield values from steady-state fluorescence measurements were calculated for the anion form using fluorescein in $0.1 \mathrm{M} \mathrm{NaOH}$ as a reference $\left(\phi_{\text {fluo }}=0.95\right)$. The quantum yield of the neutral form was obtained by fitting the steady-state fluorescence spectra to the equilibrium equation 5 once the values of $\phi_{\mathrm{A}}$ were known.

$F\left(\lambda_{\text {ex }}, \lambda_{\text {em }},\left[\mathrm{H}^{+}\right]\right)=C^{d y e} K_{a}\left[\phi_{N} \varepsilon_{N} \alpha_{N}+\phi_{A} \varepsilon_{A} \alpha_{A}\right]$

Results showed the "on/off” characteristics of this dye obtaining a quantum yield of 0.677 and 0.014 , respectively for the anionic and neutral species. It is remarkable the value of the anionic form is 50 times higher than the neutral one, that keeps a value close to zero.

\section{Exited State Proton transfer reaction studies}

The theory and methods of solving buffer-mediated ESPT reactions are well-stablished $[17,21-23]$. 
<smiles>COc1cc(C(C)C)ccc1-c1c2cc(F)c(=O)cc-2oc2cc(O)c(F)cc12</smiles>

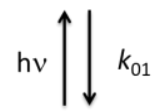<smiles>COc1cc(C(C)C)ccc1-c1c2cc(F)c(=O)cc-2oc2cc(O)c(F)cc12</smiles>

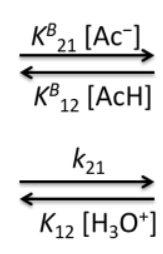<smiles>COc1cc(C(C)C)ccc1-c1c2cc(F)c(=O)cc-2oc2cc([O-])c(F)cc12</smiles><smiles>COc1cc(C(C)C)ccc1-c1c2cc(F)c(=O)cc-2oc2cc([O-])c(F)cc12</smiles>

Scheme2. Kinetic model of ground- and excited-state proton-transfer reactions of compound Iso-PG in presence of acetate buffer.

If the photophysical system as shown in Scheme 2 is excited by an infinitely short light pulse that does not significantly alter the concentrations of the ground-state species, then the fluorescence $\delta$-response function, $f\left(\lambda_{\mathrm{em}}, \lambda_{\mathrm{ex}}, t\right)$, at emission wavelength $\lambda_{\mathrm{em}}$ due to excitation at $\lambda_{\text {ex }}$ is given by

$$
f\left(\lambda_{\text {ex }}, \lambda_{\text {em }}, t\right)=p_{1} e^{\gamma_{1} t}+p_{2} e^{\gamma_{2} t} \quad t \geq 0
$$

in which equation 6 has been written in the common biexponential format,where

$$
\begin{aligned}
& \gamma_{1,2}=\frac{-(a+c) \mu \sqrt{(c-a)^{2}+4 b d}}{2} \\
& a=k_{01}+k_{21}+k^{B}{ }_{21}[R] ; \\
& b=k_{12}\left[H^{+}\right]+k^{B}[R H] ; \\
& c=k_{02}+k_{12}\left[H^{+}\right]+k^{B}{ }_{12}[R H] \\
& d=k_{21}+k^{B}{ }_{21}[R] .
\end{aligned}
$$


$[R]$ and $[R H]$ are related to the total buffer concentration, $C^{B}=[\mathrm{R}]+[R H]$, by the expressions $[R H]=C^{B}\left[H^{+}\right] /\left(\left[H^{+}\right]+K_{a}^{B}\right)$ and $[R]=C^{B} K_{a}^{B} /\left(\left[H^{+}\right]+K_{a}^{B}\right)$, where $K_{a}^{B}$ is the dissociation constant for the reversible reaction $R H \leftrightarrow R+H^{+}$.

The $\gamma$ factors are related to the lifetimes $\tau_{1}$ and $\tau_{2}$ by the expression

$$
\tau_{1,2}=-\frac{1}{\gamma_{1,2}} .
$$

For a complete characterization of the excited state, we firstly measured the fluorescence lifetime of the dye at different $\mathrm{pH}$ values between 3.82 and 7.61 in absence of acetic acid/acetate buffer. The decay curves were registered using two different excitation (440 and $485 \mathrm{~nm}$ ) and four emission wavelengths (500, 510, 520 and $530 \mathrm{~nm})$. A global analysis was carried out with the complete decay curves and a monoexponential character was found above a $\mathrm{pH}$ value of 4.1, resulting a fluorescence lifetime value of $3.290 \pm$ $0.010 \mathrm{~ns}$, corresponding with the anion form. Below pH 4.00 the decays curves were characterized by a biexponential character obtaining the same 3.29 ns fluorescence lifetime and other with a value of $0.020 \pm 0.001 \mathrm{~ns}$ corresponding with the neutral specie.

However, to resolve the acetic acid/acetate-mediated ESPT reaction was necessary to carry out a deepest study using different buffer concentration $(0,0.07,0.175,0.35$ and $0.7 \mathrm{M}$ ), three different emission wavelengths and $\mathrm{pH}$ values. Combining all of these variables a total of 135 decay traces were recorded. Using equations 6-12 we could resolve the system and obtain the rate constants involved in the decay processes and in the buffer mediated ESPT reaction. The results obtained are shown in table 1.

Table 1. Estimated Rate Constant Values by Compartmental Analysis of the Fluorescence Decay Surface

\begin{tabular}{|c|c|}
\hline Kinetic constant & Value \\
\hline $\mathrm{k}_{01}\left(\mathrm{~s}^{-1}\right)$ & $(5.01 \pm 0.72) \times 10^{10}$ \\
\hline $\mathrm{k}_{02}\left(\mathrm{~s}^{-1}\right)$ & $(3.040 \pm 0.006) \times 10^{8}$ \\
\hline $\mathrm{k}^{\mathrm{B}}{ }_{12}\left(\mathrm{M}^{-1} \mathrm{~s}^{-1}\right)$ & $(4.21 \pm 0.09) \times 10^{8}$ \\
\hline $\mathrm{k}^{\mathrm{B}}{ }_{21}\left(\mathrm{M}^{-1} \mathrm{~s}^{-1}\right)$ & $(4.13 \pm 0.72) \times 10^{10}$ \\
\hline
\end{tabular}


To asseverate the validity of the kinetic constants, we simulated the fluorescence lifetime at different $\mathrm{pH}$ values using the same buffer concentration that the one used in the experimental study. Figure 4A shows the experimental data (points) and simulation (curves) using the kinetic constants from Table 1. As can be observed, there is an excellent similarity between the experimental fluorescence lifetimes and the simulations. Therefore, kinetic constants and equations are a useful tool to estimate acetic acid/acetate concentration in samples measuring the fluorescence lifetime at any $\mathrm{pH}$ below $\sim 6.00$.

A

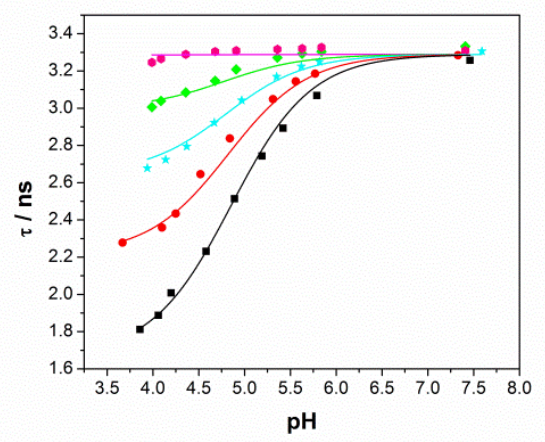

$\mathrm{B}$

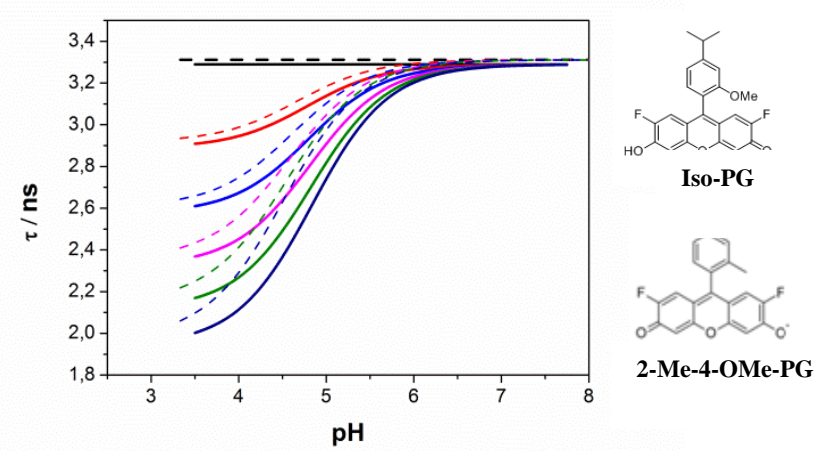

Figure 4.A) Dependence of the decay times $\tau$ on $\mathrm{pH}$ at the buffer concentrations of 0 (pink), 0.07 (green) 0.1750 (blue), 0.35 (red) and $0.7 \mathrm{M}$ (black). The decay times (solid lines) have been calculated according to equations 6-12 using the globally estimated rate constant values compiled in Table 1 B) Simulation of fluorescence lifetime from rate constant for Iso-PG ( solid line) and previous dye ()$^{[5]}$ (dashed line)

More interestingly, when we compared the sensitivity of our dye to acetic acid/acetate buffer with similar dyes, a higher dependence of the fluorescence lifetime with the buffer concentration could be found for Iso-PG. In this sense, Figure 4B illustrates the simulations of Iso-PG (solid lines) and its immediate precursor, the 2-Me-4-OMe-PG ${ }^{[5]}$ (dashed lines), showing again a higher decrease of fluorescence lifetime for Iso-PG. Thus, both the higher sensitivity and the possibility of achieving an easy quantification of acetate anion makes this dye a better choice in liquid samples.

\section{Competitive studies with other anions}

As this dye can be potentially used as acetate probe as biomarker of alcoholism, we checked by time resolved fluorescence the effect of most common anions present in blood 
medium ( $\mathrm{KCl}$ and sodium monohydrogen phosphate) at $\mathrm{pH} 4.2$ at usual concentration, i.e. $4 \mathrm{mM}$ and $2 \mathrm{mM}$ respectively. Two fluorescence lifetimes of $3.24 \mathrm{~ns}(\mathrm{KCl})$ and 3.28 ns $\left(\mathrm{H} \mathrm{Na}_{2} \mathrm{PO}_{4}\right)$ were obtained. As we have not obtained a change in the fluorescence lifetime in the presence of these salts, we can conclude that at usual concentrations these anions do not cause ESPT reaction. Finally, we performed some experiments in artificial serum using FLIM to asseverate the capacity of this dye to detect changes in acetate concentration. Figure 5A shows the FLIM images obtained using different acetate concentrations $(0,100,200,300,400$ and $600 \mathrm{mM})$. As can be observed, using an arbitrary colour scale representing the lifetime (from 1.5 to 3.2), an intense colour change is appreciated with the incorporation of acetate buffer. In Figure 5B, the increment of lifetime over the acetate concentration is represented.

A

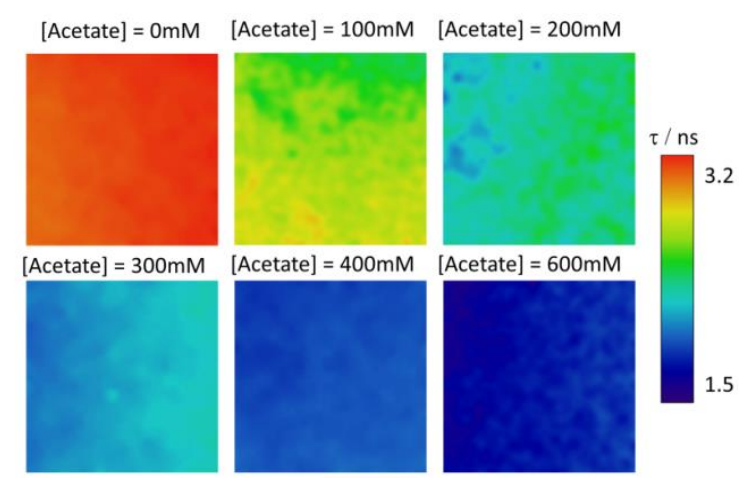

B

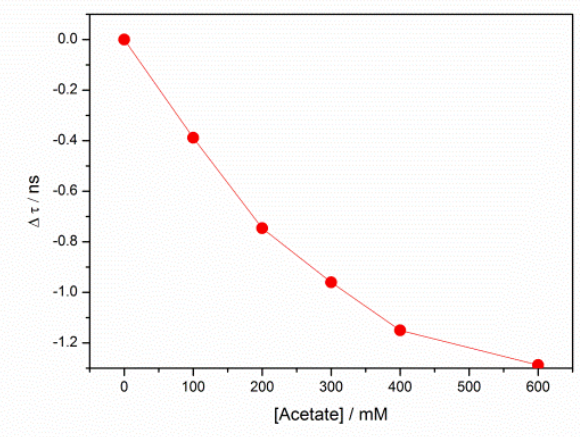

Figure 5.A) FLIM images obtained in artificial serum using different acetate concentratiosn $(0,100,200,300,400$ and $600 \mathrm{mM})$. B) Average lifetime vs acetate concentration

\section{Conclusions}

We have studied the photophysics of a new fluorescent compound. The most remarkable characteristic is the "on/off" property. The buffer mediated ESPT reaction has been deeply studied and the kinetic constant recovered. Moreover, combining the kinetic constant and the theoretical equations it is possible to determine the acetate concentration in a liquid sample. As a proof of concept, considering that this dye can be potentially used as acetate probe in live samples we have used it to measure its concentration in artificial serum. 


\section{Acknowledgments}

This work was supported by the Ministerio Español de Ciencia e Innovación (co-financed

by FEDER funds) through grants CTQ2014-56370, CTQ2017-85658-R; and Project

FQM2012-790 (Junta de Andalucía, Spain).

\section{Bibliography}

[1] J.L. Kolanowski, F. Liu, E.J. New, Fluorescent probes for the simultaneous detection of multiple analytes in biology, Chemical Society Reviews, 47(2018) 195-208.

[2] H. Xie, J. Mire, Y. Kong, M. Chang, H.A. Hassounah, C.N. Thornton, J.C. Sacchettini, J.D. Cirillo, J. Rao, Rapid point-of-care detection of the tuberculosis pathogen using a BlaC-specific fluorogenic probe, Nature chemistry, 4(2012) 802-9.

[3] Z. Yang, A. Sharma, J. Qi, X. Peng, D.Y. Lee, R. Hu, D. Lin, J. Qu, J.S. Kim, Super-resolution fluorescent materials: an insight into design and bioimaging applications, Chemical Society Reviews, 45(2016) 4651-67.

[4] L.M. Wysocki, J.B. Grimm, A.N. Tkachuk, T.A. Brown, E. Betzig, L.D. Lavis, Facile and General Synthesis of Photoactivatable Xanthene Dyes, Angewandte Chemie (International Ed in English), 50(2011) 11206-9.

[5] V. Puente-Muñoz, J.M. Paredes, S. Resa, A.M. Ortuño, E.M. Talavera, D. Miguel, J.M. Cuerva, L. Crovetto, Efficient acetate sensor in biological media based on a selective Excited State Proton Transfer (ESPT) reaction, Sensors and Actuators B: Chemical, 250(2017) 623-8.

[6] Y. Urano, M. Kamiya, K. Kanda, T. Ueno, K. Hirose, T. Nagano, Evolution of Fluorescein as a Platform for Finely Tunable Fluorescence Probes, J Am Chem Soc, 127(2005) 4888-94.

[7] L. Mottram, S. Boonyarattanakalin, R.E. Kovel, B.R. Peterson, The Pennsylvania Green Fluorophore: A Hybrid of Oregon Green and Tokyo Green for the Construction of Hydrophobic and pH-Insensitive Molecular Probes, Organic Letters, 8(2006) 581-4.

[8] U.-M. Korri, H. Nuutinen, M. Salaspuro, Increased Blood Acetate: A New Laboratory Marker of Alcoholism and Heavy Drinking, Alcoholism: Clinical and Experimental Research, 9(1985) 468-71.

[9] R.P. Roine, U.-M. Korri, R. Ylikahri, A. Penttilä, J. Pikkarainen, M. Salaspuro, INCREASED SERUM ACETATE AS A MARKER OF PROBLEM DRINKING AMONG DRUNKEN DRIVERS, Alcohol and Alcoholism, 23(1988) 123-6.

[10] N. Boens, N. Basarić, E. Novikov, L. Crovetto, A. Orte, E.M. Talavera, J.M. Alvarez-Pez, Identifiability of the Model of the Intermolecular Excited-State Proton Exchange Reaction in the Presence of pH Buffer, The Journal of Physical Chemistry A, 108(2004) 8180-9.

[11] W. Qin, N. Basarić, N. Boens, Experimental Design for the Estimation of Photophysical Parameters of the Two-State Excited-State Proton-Exchange Reaction in the Presence of $\mathrm{pH}$ Buffer, The Journal of Physical Chemistry A, 109(2005) 4221-30.

[12] S.A. Comerford, Z. Huang, X. Du, Y. Wang, L. Cai, A.K. Witkiewicz, H. Walters, M.N. Tantawy, A. Fu, H.C. Manning, J.D. Horton, R.E. Hammer, S.L. McKnight, B.P. Tu, Acetate Dependence of Tumors, Cell, 159(2014) 1591-602.

[13] T. Mashimo, K. Pichumani, V. Vemireddy, K.J. Hatanpaa, D.K. Singh, S. Sirasanagandla, S. Nannepaga, S.G. Piccirillo, Z. Kovacs, C. Foong, Z.G. Huang, S. Barnett, B.E. Mickey, R.J. DeBerardinis, B.P. Tu, E.A. Maher, R.M. Bachoo, Acetate Is a Bioenergetic Substrate for Human Glioblastoma and Brain Metastases, Cell, 159(2014) 1603-14.

[14] C.A. Lyssiotis, L.C. Cantley, Acetate Fuels the Cancer Engine, Cell, 159(2014) 1492-4. 
[15] L. Han, S.O. Enfors, L. Haggstrom, Changes in intracellular metabolite pools, and acetate formation in Escherichia coli are associated with a cell-density-dependent metabolic switch, Biotechnol Lett, 24(2002) 483-8.

[16] A.S. Ciggin, M. Majone, D. Orhon, Intracellular storage of acetate/starch mixture by fast growing microbial culture in sequencing batch reactor under continuous feeding, Bioresour Technol, 119(2012) 331-8.

[17] A. Martinez-Peragon, D. Miguel, A. Orte, A.J. Mota, M.J. Ruedas-Rama, J. Justicia, J.M. Alvarez-Pez, J.M. Cuerva, L. Crovetto, Rational design of a new fluorescent 'ON/OFF' xanthene dye for phosphate detection in live cells, Org Biomol Chem, 12(2014) 6432-9.

[18] S. Resa, A. Orte, D. Miguel, J.M. Paredes, V. Puente-Muñoz, R. Salto, M.D. Giron, M.J. Ruedas-Rama, J.M. Cuerva, J.M. Alvarez-Pez, L. Crovetto, New Dual Fluorescent Probe for Simultaneous Biothiol and Phosphate Bioimaging, Chemistry - A European Journal, 21(2015) 14772-9.

[19] A. Martinez-Peragon, D. Miguel, A. Orte, A.J. Mota, M.J. Ruedas-Rama, J. Justicia, J.M. Alvarez-Pez, J.M. Cuerva, L. Crovetto, Rational design of a new fluorescent 'ON/OFF' xanthene dye for phosphate detection in live cells, Organic \& biomolecular chemistry, 12(2014) 6432-9.

[20] A. Orte, L. Crovetto, E.M. Talavera, N. Boens, J.M. Alvarez-Pez, Absorption and emission study of 2 ',7 '-difluorofluorescein and its excited-state buffer-mediated proton exchange reactions, Journal of Physical Chemistry A, 109(2005) 734-47.

[21] J.M. Alvarez-Pez, L. Ballesteros, E. Talavera, J. Yguerabide, Fluorescein Excited-State Proton Exchange Reactions: Nanosecond Emission Kinetics and Correlation with Steady-State Fluorescence Intensity, J Phys Chem A, 105(2001) 6320-32.

[22] L. Crovetto, J.M. Paredes, R. Rios, E.M. Talavera, J.M. Alvarez-Pez, Photophysics of a Xanthenic Derivative Dye Useful as an 'On/Off' Fluorescence Probe, J Phys Chem A, 111(2007) 13311-20.

[23] L. Crovetto, A. Orte, E.M. Talavera, J.M. Alvarez-Pez, M. Cotlet, J. Thielemans, F.C. De Schryver, N. Boens, Global compartmental analysis of the excited-state reaction between fluorescein and (+/-)-N-acetyl aspartic acid, Journal of Physical Chemistry B, 108(2004) 608292. 